\title{
Different expression of mimecan as a marker for differential diagnosis between NSCLC and SCLC
}

\author{
CUI-XIA ZHENG ${ }^{1 *}$, SHUANG-XIA ZHAO ${ }^{2 *}$, PING WANG ${ }^{3 *}$, HUI-MIN YU ${ }^{2}$, \\ CAO-FU WANG ${ }^{3}$, BING HAN ${ }^{2}$, BIN SU $^{2}$, YI XIANG ${ }^{4}$, XUE-SONG LI ${ }^{2}$, SHENG-XIAN LI ${ }^{2}$, \\ QIN-YUN MA ${ }^{2}$, RONG-XIN ZHANG ${ }^{3}$, HUAN-YING WAN ${ }^{4}$ and HUAI-DONG SONG ${ }^{2}$
}

\author{
${ }^{1}$ The Ninth Hospital, Shanghai Jiaotong University School of Medicine, 639 Zhizaoju Rd., Shanghai 200011; \\ ${ }^{2}$ Center of Molecular Medicine, Shanghai Institute of Endocrinology, State Key Laboratory of Medical Genomics, \\ Ruijin Hospital, Shanghai Jiaotong University School of Medicine, 197, Ruijin Rd. II, Shanghai 200025; \\ ${ }^{3}$ Department of Pathology, Bengbu Medical College, Bengbu, Anhui Province 233003; ${ }^{4}$ Department of Respiratory, \\ Ruijin Hospital, Shanghai Jiaotong University School of Medicine, 197, Ruijin Rd. II, Shanghai 200025, P.R. China
}

Received May 27, 2009; Accepted July 16, 2009

DOI: 10.3892/or_00000536

\begin{abstract}
Mimecan mRNA was present in a limited number of mouse and human tissues, however, abundant mimecan mRNA was observed in the lung tissue. Therefore, we hypothesize that mimecan could serve as a biomarker for differentiating various histological types of lung cancers. In humans, the mimecan mRNA was found most abundant in ovary and less abundant in lung by using Northern blot analysis. Moreover, the mimecan was expressed strongly in the epithelial cells of the bronchial wall and weaker in the epithelial cells of the alveolar sacs by in situ hybridization and immunohistochemical analysis. Furthermore, the mimecan immunoreactivity was found in $103(97.2 \%)$ of 106 non-small cell lung cancers (NSCLCs). Nevertheless, a large majority of small cell lung cancers (SCLCs) $(50 / 56,89.3 \%)$ showed negative immunoreactivity to mimecan polyclonal antibody. A significant difference of mimecan immunoreactivity was found between NSCLC and SCLC $(\mathrm{P}<0.00001)$. This is the first study showing that mimecan could serve as an excellent pathological biomarker to distinguish NSCLCs from SCLCs.
\end{abstract}

\section{Introduction}

Mimecan/osteoglycin, isolated from bone, was originally called osteoinductive factor and later renamed mimecan/osteoglycin

Correspondence to: Dr Cui-Xia Zheng, The Ninth Hospital, Shanghai Jiaotong University School of Medicine, 639 Zhizaoju Rd., Shanghai 200011, P.R. China

E-mail: zcx9566@163.com

${ }^{*}$ Contributed equally

Key words: non-small cell lung cancers, small cell lung cancers, mimecan, molecular biomarker, differential diagnosis
(1-3). It belongs to a family of small leucine-rich proteoglycans (SLRPs) that are secreted into the extracellular matrix. SLRPs, being abundant in bone matrix, cartilage cells and connective tissues, are important for collagen fibrillogenesis, cellular growth, differentiation and migration. The genomic structure of mimecan is highly conserved among species, a single copy gene gives rise to multiple mRNA transcripts, resulted from differential splicing and alternative polyadenylation (4). However, all mimecan mRNAs produce an identical protein that is conserved among mice, bovine, and human beings, suggesting its functional importance $(3,5,6)$. The mimecan gene encodes a $34 \mathrm{kDa}$ full-length protein which has been named mimecan. However, a $12-\mathrm{kDa}$ mature protein corresponding to the 105 carboxyl-terminal amino acids of mimecan has been isolated from bovine bone $(1,3,5)$; whilst a $25-\mathrm{kDa}$ keratan sulfate glycoprotein corresponding to the 223 carboxyl-terminal amino acids of mimecan has been isolated from bovine cornea $(3,7,8)$. Up to now, the physiological function of mimecan has not been fully elucidated. Initial studies showed that mimecan could induce ectopic bone formation and subcutaneous implantation of mimecan plus transforming growth factor $\beta$ (TGF- $\beta$ ) type 1 or 2 into rats induced the bone formation at the implantation site (9). However, further study showed that co-purifying bone morphogenic proteins in mimecan preparation were the sources of the growth stimulatory activity (3). Interestingly, the tumor suppressor protein p53 could activate transcription of bovine and human mimecan genes (10-12). Furthermore, human mimecan mRNA was absent or at low levels in a majority of cancer cell lines and tumors, where p53 was frequently inactivated/mutated (10-12).

In our recent study, we found that mimecan mRNA was present in a limited number of mouse (10) and human tissues. In mouse, mimecan was found most abundant in the lung tissue, whereas in human tissues it was found most abundant in the ovary, and less abundant in lung, adrenal gland, esophagus and heart by using Northern blot analysis. Moreover, the mimecan was expressed strongly in the epithelial cells of the bronchial wall, and weaker in the 
epithelial cells of the alveolar sacs in mouse and human by in situ hybridization and immunohistochemical analysis. Therefore, it is tempting to presume that the secretive protein mimecan may be useful as a biomarker to play a role in the differential diagnosis of lung cancers. To address this issue, the mimecan expression in different histological types of lung cancers was detected by using immunohistochemical analysis. Our results suggested that mimecan could act as a biomarker to play a role in identifying different histological types of lung cancers.

\section{Materials and methods}

Northern blot analysis. Northern blot analysis was performed using non-isotopic DIG Northern starter kit (Roche) according to the manufacturer's protocol. Target fragments, human mimecan and GAPDH, were cloned into PGEM-T easy vector and confirmed by restriction enzyme digestion and sequence analysis. DIG-labeled probes were generated by transcription with SP6/T7 RNA polymerase using DIG RNA labeling kit. The human tissue specimens were obtained during surgery for clinical indications. This study was conducted according to the Institutional and Ethical rules concerning research on tissue specimens and was exempted from informed consent from the patients. Immediately after surgery, different tissues were cut into fragments of $\sim 1 \mathrm{~cm}^{3}$ each and frozen in liquid nitrogen. Total RNA from frozen tissues was prepared by TRIzol Reagent (Invitrogen). The RNA content was estimated by spectrophotometry. Ten micrograms per lane were electrophoresed on a $1.2 \%$ agarose-formaldehyde denaturing gel and were transferred by capillary blotting to positively-charged nylon membranes (Roche). The membrane was then baked at $80^{\circ} \mathrm{C}$ for $2 \mathrm{~h}$. Hybridization was performed at $68^{\circ} \mathrm{C}$ with agitation overnight. The membrane was washed twice with 2X SSC and $0.1 \%$ SDS for $5 \mathrm{~min}$ at room temperature and twice with $0.1 \mathrm{X} \mathrm{SSC}$ and $0.1 \% \mathrm{SDS}$ for $15 \mathrm{~min}$ at $68^{\circ} \mathrm{C}$. The membrane was washed and blocked and then incubated with anti-DIG serum/alkaline phosphatase conjugate. CDP-star was used as the chemiluminescence substrate. Signals were visualized on X-ray film.

In situ hybridization. The RNA probes were labeled by using the DIG RNA labeling kit (SP6/T7) (Roche). Mouse lung was obtained after they were sacrificed and human fetal lung was obtained from a 6-month dead fetus of natural abortion. The lung tissues were resected from these samples and put into $4 \%$ paraformaldehyde for fixing. Serial frozen sections $(5 \mu \mathrm{m})$ were generated from the normal lung tissues of mouse and fetus. These sections were first fixed in $4 \%$ paraformaldehyde and digested in $1 \mu \mathrm{g} / \mathrm{ml}$ protein kinase buffer; after prehybridization the sections were incubated with hybridization solution containing $0.5 \mathrm{ng} / \mu 1$ probe in a humidified chamber overnight at $68^{\circ} \mathrm{C}$. The posthybridization slides were washed twice with $2 \mathrm{X} \mathrm{SSCT} / 50 \%$ formamide at $68^{\circ} \mathrm{C}$ and once with 2X SSCT, 0.2X SSCT at room temperature and then incubated with anti-DIG-AP Fab diluted 1:1000 in blocking solution. After being washed in MABT, they were incubated with staining buffer in a humidified chamber. To terminate the reaction, samples were rinsed several times with nuclease-free water and were visualized by light microscopy.

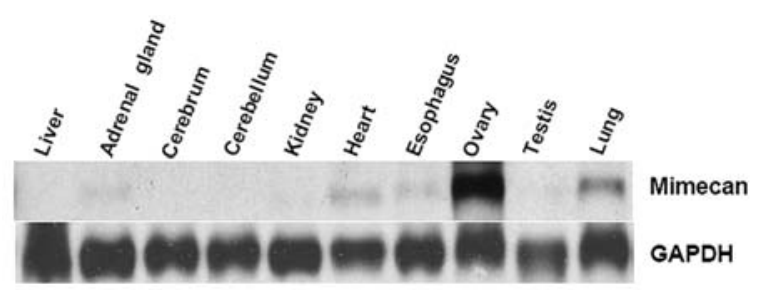

Figure 1. Mimecan gene expression in human tissues by Northern blot analysis. Total RNA (10 $\mu \mathrm{g})$ extracted from a variety of human tissues was separated by electrophoresis and transferred to nylon membranes and mRNA for the mimecan gene was detected by hybridization with DIG-labeled RNA probes as described in Materials and methods. mRNA transcripts of mimecan were detected in the adrenal gland, heart, esophagus, ovary and lung.

Patients and tissue samples. Normal adult lung tissue was obtained from a patient with lung cancer during surgery. First, primary lung tumor samples from 106 non-small cell lung cancers (NSCLCs) and 56 small cell lung cancers (SCLCs) were obtained by surgical resection and bronchoscopic biopsy, between 2001 and 2004 at the Department of Pathology, First Hospital affiliated to Beng Bu Medical College. Of the 106 NSCLCs, 77 were squamous, 25 were adenocarcinomas, 4 were large cell lung cancers. All hematoxylin-eosin-stained slides of the tissue samples were reviewed and the pathological diagnosis of the histological grades and types were confirmed by a pathologist. Histological typing was performed according to the World Health Organization diagnostic criteria for lung carcinomas (2004). Furthermore, the archival surgical histopathological materials of these cases were examined and appropriate tissue blocks selected for sectioning and staining.

Immunohistochemical analysis. Sections of formalin-fixed, paraffin-embedded lung tissue specimens (thickness of $5 \mu \mathrm{m}$ ) were rehydrated and after antigen retrieval by microwave treatment, they were immunostained with mimecan polyclonal antibody (1:1000 dilution), which was generated in our laboratory by immunizing rabbits with GST-mimecan fusion protein corresponding to the 105 most carboxyl-terminal amino acids of mimecan (13). Immunostaining was visualized with EnVision+ system (Dako, CA), followed by nuclear counterstaining with Gill's hematoxylin (Thermo-Shandon, PA). The preimmune rabbit (1:1000 dilution) serum was used as a negative control in adjacent sections.

Statistical analysis. Statistic analysis was performed with Chi-square test ( $\chi^{2}$ test). P-values $<0.05$ were considered statistically significant.

\section{Results}

Mimecan expression in normal lung tissue. In our recent study, we found that mimecan mRNA was present in a limited number of mouse tissues (13). Among these tissues mimecan was most abundant in lung and adrenal gland and less abundant in the pituitary and heart (13). However, in human tissues, the mimecan mRNA was most abundant in the ovary. Less abundant of the mimecan mRNA in lung tissue was also detected, which was relatively higher than those in adrenal gland, esophagus and heart by using Northern blot analysis (Fig. 1). The mimecan mRNA expressed in mouse and human 


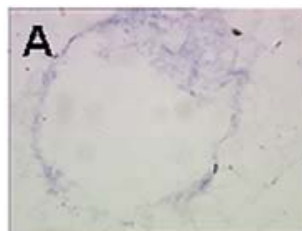

B
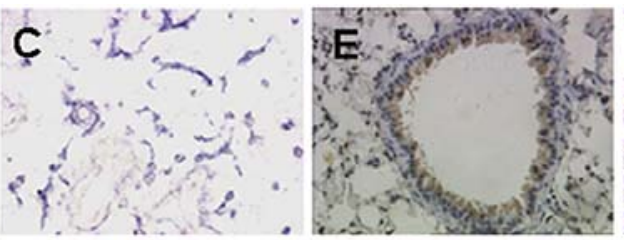

D

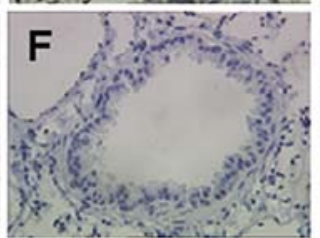

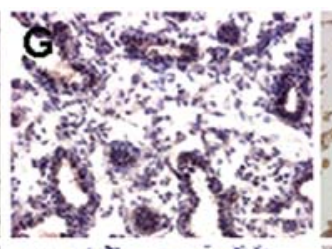
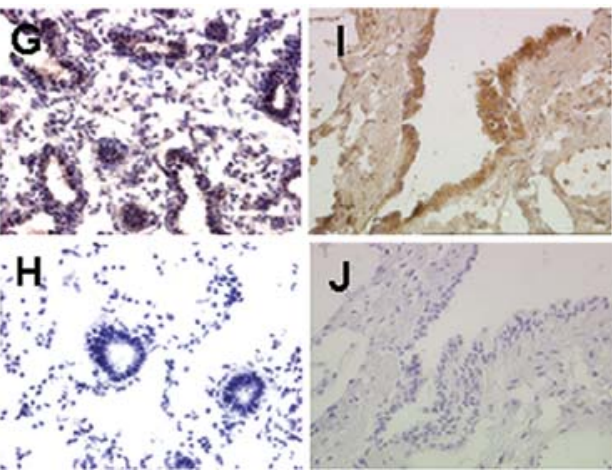

$\mathrm{J}$

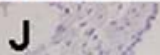

Figure 2. Mimecan expression in mice and human fetal lung tissues by in situ hybridization and immunohistochemical assay. Lung sections were hybridized with DIG-labeled probes. (A and C) Hybridization with antisense probes in mice and fetal lung tissues. Positive signals by the antisense probe were mainly detected in the wall of bronchial and respiratory bronchioles of the mouse and human fetal lung tissues. (B and D) Hybridization with sense probes as negative controls. No hybridization signals were detected in those regions by using the sense probes; ( $\mathrm{E}, \mathrm{G}$ and I) Immunolocalization of mimecan in mouse, fetus and adult lung tissue. Lung sections were stained with rabbit antimimecan antiserum (1:1000 dilution, the antibody was produced in our laboratory). Brownish diaminobenzidine precipitates were mainly located in the epithelial cells of the bronchial wall, alveolar sacs and respiratory bronchioles at various intensities; $(\mathrm{F}$, $\mathrm{H}$ and $\mathrm{J}$ ) Adjacent sections were stained with pre-immune rabbit serum (1:1000 dilution) as a negative control. Original magnification x40 (A, B, E, F, I and J), x20 (C, D, $\mathrm{G}$ and $\mathrm{H})$.

Table I. The results of mimecan expression in lung tissues in the patients with non-small cell lung cancer and small cell lung cancer.

\begin{tabular}{|c|c|c|c|c|c|}
\hline \multirow[b]{2}{*}{ Histological types } & \multicolumn{2}{|c|}{ Negative } & \multicolumn{2}{|c|}{ Positive } & \multirow[b]{2}{*}{ Total } \\
\hline & Number & Percent (\%) & Number & Percent $(\%)$ & \\
\hline \multicolumn{6}{|l|}{ NSCLC } \\
\hline SCC & 1 & 1.3 & 76 & 98.7 & 77 \\
\hline $\mathrm{ADC}$ & 2 & 8.0 & 23 & 92.0 & 25 \\
\hline LCLC & 0 & 0.0 & 4 & 100.0 & 4 \\
\hline \multicolumn{6}{|l|}{ NSCLC } \\
\hline Subtotal & 3 & 2.8 & 103 & 97.2 & 106 \\
\hline SCLC & 50 & 89.3 & 6 & 10.7 & 56 \\
\hline
\end{tabular}

lung tissues were confirmed by in situ hybridization. As shown in Fig. 2, mimecan mRNA was detected in the wall of bronchial and respiratory bronchioles of mouse and human fetus lung tissues with the anti-sense probe (Fig. 2A and C), while no signals were detected in these regions with the sense probe (Fig. 2B and D). Furthermore, the mimecan expression in the mouse (Fig. 2E and F) and human fetal lung tissues (Fig. 2G and $\mathrm{H}$ ) was investigated by using immunohistochemical analysis. As shown in Fig. 2, in normal lung tissues, cytoplasmic staining of mimecan was observed in the epithelial cells of the bronchial wall, alveolar sacs and respiratory bronchioles at various intensities. The epithelial cells of the bronchial wall were strongly reactive to mimecan protein, whereas, the staining intensity was weaker in the epithelial cells of the alveolar sacs. However, no other cells, including smooth muscle cells, interstitial cells, endothelial cells, fibroblasts, or infiltrating inflammatory cells, were detected immunoreactive with mimecan antibody (Fig. 2E-J). These results indicated that mimecan was mainly expressed in epithelial cells of the lung and therefore, could be used as a molecular marker in differentiating for neoplasms arising from this type of cell.
Mimecan protein expression in different histological types of lung cancers. To further evaluate the significance of mimecan in discriminating histological types of lung cancers, the mimecan protein expressed in 162 patients with different histological types of lung cancers was investigated by using immunohistochemical analysis. Data on mimecan immunoreactivity in lung tumors are summarized in Table I. Overall, mimecan immunoreactivity was found in 103 (97.2\%) of 106 NSCLCs, including $76(98.7 \%)$ of 77 squamous cell carcinomas (SCC), 23 (92\%) of 25 adenocarcinomas (ADC) and $4(100 \%)$ of 4 large cell lung cancers (LCLC) (Table I, Fig. 3). However, the majority of cases with SCLCs (50/56, $89.3 \%$ ) showed negative immunoreactivity to mimecan polyclonal antibody (Table I, Fig. 3). A significant difference in mimecan immunoreactivity was found between the two groups: SCLC and NSCLC ( $\mathrm{P}<0.00001)$. When we compared mimecan expression in SCLC with that in SCC or adenocarcinoma, the difference remained significant, with both at P-values of $<0.00001$. 

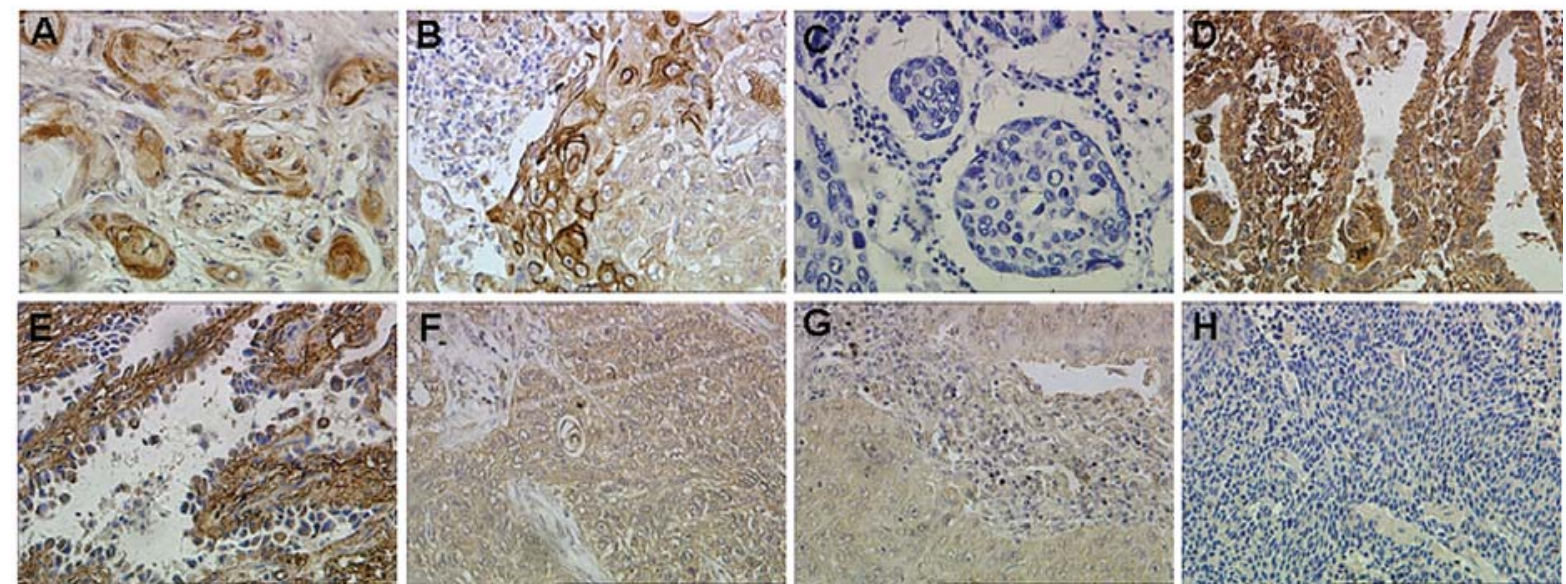

Figure 3. Mimecan protein expression in the tissues of patients with NSCLC or SCLC by using an immunohistochemical assay. Lung cancer sections were immunostained with rabbit polyclonal antibody of mimecan (1000-fold dilution). Brownish diaminobenzidine precipitates were the result of a positive reaction of mimecan. The preimmune rabbit serum (1000-fold dilution) was used as a negative control in adjacent sections. (A-C) Well and poorly differentiated lung squamous carcinomas with high expression of mimecan (A and B) or without mimecan expression (C); (D and E) Well and poorly differentiated lung adenocarcinomas with high expression of mimecan; ( $\mathrm{F}$ and $\mathrm{G}$ ) Large cell and clear cell lung cancers; (H) Small cell lung cancer without mimecan expression. Almost all the NSCLC expressed mimecan protein. Original magnification, $\mathrm{x} 40$.

\section{Discussion}

According to different morphological features, lung cancers could be divided mainly into two categories: SCLC and NSCLC, which treated differently and have different prognosis. SCLC account for $\sim 20 \%$ of new cases of lung cancer. SCLC is also an aggressive neoplasm of rapid growth, often presenting with metastases in regional lymph nodes or distant organs at the time of diagnosis, but with high sensitivity to chemotherapy and radiotherapy (14). NSCLC comprise three major histological subtypes, namely lung adenocarcinoma (LADC), lung squamous cell cancer (SCC) and large cell lung cancer (LCLC) for which surgery is the only chance for cure (14). The correct diagnosis of SCLC or NSCLC is very important for prognostic and therapeutic reasons, due to their different behaviors. Differentiation between SCLC and NSCLC mainly depend on the histology. However, even an experienced pathologist may have difficulty in making correct diagnosis in some lung cancers, such as poorly differentiated lung cancer and SCLC. In this situation, tumor markers may serve as a useful alternative diagnostic method. Many studies have shown that expression of different biomarkers are frequent in various histological types of lung cancers and many authors have considered the presence of these markers in serum as an index of extension of disease, prognosis and response to therapy (15). Some tumor markers have been extensively studied in lung cancer, such as carcinoembryonic antigen (CEA), SCC and cytokeratins CYFRA-21.1 are studied most extensively in non-small cell lung cancer (NSCLC) and neuron-specific enolase (NSE), ProGRP and chromogranin A in small cell lung cancer (SCLC) (16-20). However, application of these markers in diagnosis of lung cancers and in differentiating the histological types of the tumors has not been satisfactory, even though a relationship with clinical relevance has been found for the NSE and ProGRP markers in SCLC $(18,19)$ and the CYFRA 21-1 marker, on the other hand, has been useful only in follow-up of NSCLC of the squamous subtype (21). In previous years, CD56 has become the antibody of choice in many laboratories because the sensitivities for other antibodies in small cell lung carcinoma vary, and comparative studies suggest that CD56 is the most sensitive in these markers for different diagnosing the SCLC from NSCLC $(22,23)$. In a previous study, Kaufmann et al reported that the monoclonal antibody $123 \mathrm{C} 3$ for CD56 showed diffusely stained in most small cell carcinomas with a strong membranous pattern (sensitivity: 0.99). The other neuroendocrine markers had a combined sensitivity of only 0.44 for small cell carcinomas. However, only 7 of 93 NSCLC $(7.5 \%)$ showed positive immunoreactivity for CD56 monoclonal antibody (24). Notably, in contrast to the marker of CD56, we first described that the secreted protein mimecan was expressed in NSCLC tissues in the present study. The mimecan immunoreactivity was found in 103 (97.2\%) of 106 NSCLCs, including $76(98.7 \%)$ of 77 squamous cell carcinomas (SCC), 23 (92\%) of 25 adenocarcinomas (ADC) and 4 (100\%) of 4 large cell lung cancers, whereas, only a few cases of SCLC $(6 / 56,10.7 \%)$ showed positivity for mimecan protein (Table I, Fig. 3). A significant difference in mimecan immunoreactivity was found between the two groups: SCLC and NSCLC $(\mathrm{P}<0.00001)$. These data suggest that mimecan might be useful for the immunohistochemical differentiation of NSCLC from small cell lung carcinoma on paraffin sections, especially in some conditions, which poorly differentiated lung cancers of NSCLC might be misinterpreted as SCLC. As a rule, mimecan immunostaining can be used as an ancillary diagnostic method in the differential diagnosis between NSCLC and SCLC. However, due to the expression patterns of these two biomarkers were mutually exclusive in human different histological types of lung cancers, it is intriguing to evaluate the values of mimecan compared with other widely used biomarkers such as CD56 in identifying different histological types of lung cancers in further studies. 


\section{Acknowledgements}

This study was supported in part by the National Natural Science Foundation of China (30530370, 30771017 and 30470816), Chinese High Tech Program (863) (2006AA02Z 175), Commission for Science and Technology of Shanghai (055407029, 06XD14016 and 06JC14054).

\section{References}

1. Bentz H, Nathan RM, Rosen DM, Armstrong RM, Thompson AY, Segarini PR, Mathews MC, Dasch JR, Piez KA and Seyedin SM: Purification and characterization of a unique osteoinductive factor from bovine bone. J Biol Chem 264: 20805-20810, 1989.

2. Bentz H, Thompson AY, Armstrong R, Chang RJ, Piez KA and Rosen DM: Transforming growth factor-beta 2 enhances the osteoinductive activity of a bovine bone-derived fraction containing bone morphogenetic protein-2 and 3. Matrix 11: 269-275, 1991.

3. Funderburgh JL, Corpuz LM, Roth MR, Funderburgh ML Tasheva ES and Conrad GW: Mimecan, the 25-kDa corneal keratan sulfate proteoglycan, is a product of the gene producing osteoglycin. J Biol Chem 272: 28089-28095, 1997.

4. Tasheva ES, Corpuz LM, Funderburgh JL and Conrad GW: Differential splicing and alternative polyadenylation generate multiple mimecan mRNA transcripts. J Biol Chem 272: 32551-32556, 1997.

5. Madisen L, Neubauer M, Plowman G, Rosen D, Segarini P, Dasch J, Thompson A, Ziman J, Bentz H and Purchio AF: Molecular cloning of a novel bone-forming compound: osteoinductive factor. DNA Cell Biol 9: 303-309, 1990.

6. Ujita M, Shinomura T and Kimata K: Molecular cloning of the mouse osteoglycin-encoding gene. Gene 158: 237-240, 1995.

7. Funderburgh JL and Conrad GW: Isoforms of corneal keratan sulfate proteoglycan. J Biol Chem 265: 8297-8303, 1990.

8. Funderburgh JL, Funderburgh ML, Mann MM and Conrad GW: Unique glycosylation of three keratan sulfate proteoglycan isoforms. J Biol Chem 266: 14226-14231, 1991

9. Kukita A, Bonewald L, Rosen D, Seyedin S, Mundy GR and Roodman GD: Osteoinductive factor inhibits formation of human osteoclast-like cells. Proc Natl Acad Sci USA 87: 3023-3026, 1990.

10. Tasheva ES, Maki CG, Conrad AH and Conrad GW: Transcriptional activation of bovine mimecan by p53 through an intronic DNA-binding site. Biochim Biophys Acta 1517: 333-338, 2001.

11. Tasheva ES, Koester A, Paulsen AQ, Garrett AS, Boyle DL, Davidson HJ, Song M, Fox N and Conrad GW: Mimecan/ osteoglycin-deficient mice have collagen fibril abnormalities. Mol Vis 8: 407-415, 2002.

12. Tasheva ES: Analysis of the promoter region of human mimecan gene. Biochim Biophys Acta 1575: 123-129, 2002.
13. Hu SM, Li F, Yu HM, Li RY, Ma QY, Ye TJ, Lu ZY, Chen JL and Song HD: The mimecan gene expressed in human pituitary and regulated by pituitary transcription factor- 1 as a marker for diagnosing pituitary tumors. J Clin Endocrinol Metab 90: 6657-6664, 2005

14. Molina R, Filella X and Auge JM: ProGRP: a new biomarker for small cell lung cancer. Clin Biochem 37: 505-511, 2004.

15. Tarro G, Perna A and Esposito C: Early diagnosis of lung cancer by detection of tumor liberated protein. J Cell Physiol 203: 1-5, 2005.

16. Niklinski J, Furman M, Laudanski J and Kozlowski M: Prognostic value of pretreatment CEA, SCC-Ag and CA 19-9 levels in sera of patients with non-small cell lung cancer. Eur J Cancer Prev 1: 401-406, 1992.

17. Molina R, Filella X, Auge JM, Fuentes R, Bover I, Rifa J, Moreno V, Canals E, Viñolas N, Marquez A, Barreiro E, Borras J and Viladiu P: Tumour markers (CEA, CA125, CYFRA 21-1, SCC and NSE) in patients with non-small cell lung cancer as aid in histological diagnosis and prognosis: comparison with the main clinical and pathological prognostic factors. Tumor Biol 24: 209-218, 2003.

18. Niho S, Nishiwaki Y, Goto K, Ohmatsu H, Matsumoto T, Hojo F, Ohe Y, Kakinuma R and Kodama T: Significance of serum progastrin-releasing peptide as a predictor of relapse of small cell lung cancer: comparative evaluation with neuron-specific enolase and carcinoembryonic antigen. Lung Cancer 27: 159-167, 2000.

19. Lamy PJ, Grenier J, Kramar A and Pujol JL: Pro-gastrin-releasing peptide, neuron specific enolase and chromogranin A as serum markers of small cell lung cancer. Lung Cancer 29: 197-203, 2000.

20. Hage R, Elbers HR, Brutel de la Rivière A and van den Bosch JM: Neural cell adhesion molecule expression: prognosis in 889 patients with resected non-small cell lung cancer. Chest 114 . 1316-1320, 1998.

21. Ando S, Kimura H, Iwai N, Shima M, Ando M and Kuriyama T: Optimal combination of seven tumor markers in prediction of advanced stage at first examination of patients with non-small cell lung cancer. Anticancer Res 21: 3085-3092, 2001.

22. Lantuejoul S, Moro D, Michalides RJ, Brambilla C and Brambilla E: Neural cell adhesion molecule (NCAM) and NCAM-PSA expression in neuroendocrine lung tumors. Am J Surg Pathol 22: 1267-1276, 1998.

23. Kibbelaar RE, Moolenaar KE, Michalides RJ, Van Bodegom PC, Vanderschueren RG, Wagenaar SS, Dingemans KP, BitterSuermann D, Dalesio O and Van Zandwijk N: Neural cell adhesion molecule expression, neuroendocrine differentiation and prognosis in lung carcinoma. Eur J Cancer 24: 431-435, 1991.

24. Kaufmann O, Georgi T and Dietel M: Utility of $123 \mathrm{C} 3$ monoclonal antibody against CD56 (NCAM) for the diagnosis of small cell carcinomas on paraffin sections. Hum Pathol 28: 1373-1378, 1997. 